\title{
Sensory Disorder
}

National Cancer Institute

\section{Source}

National Cancer Institute. Sensory Disorder. NCI Thesaurus. Code C63711.

An interruption or alteration in the sensory activity or functions of the nervous system. 